\title{
Identifikasi Struktur
}

\section{Lapisan Bawah Permukaan Daerah Potensial Mineral dengan Menggunakan Metode Gravitasi di Lapangan "A", Pongkor, Jawa Barat}

\author{
Nurin Wachidah, Eko Minarto \\ Departemen Fisika, Fakultas Ilmu Alam, Institut Teknologi Sepuluh Nopember (ITS) \\ e-mail:eko.minarto@googlemail.com
}

\begin{abstract}
Abstrak-Indonesia memiliki banyak potensi tambang mineral sehingga memerlukan survey dan analisis agar dapat memanfaatkan potensi tersebut. Salah satu metode yang dapat digunakan adalah dengan menggunakan metode geofisika. Oleh karena dilakukan penelitian menggunakan metode gravitasi di daerah Pongkor, Jawa Barat. Pengambilan data gravitasi dilakukan pada 23 Maret hingga 27 Mei Juli 2013 menggunakan alat gravitimeter SCINTREX AUTOGRAV CG-5 dengan 193 titik pengukuran. Anomali Bouguer Lengkap di topografi direduksi ke bidang datar menggunakan metode Dampney. Kemudian dilakukan pemisahan anomali regional dan residual dengan menggunakan metode kontinuasi ke atas pada ketinggian 300 meter. Pemodelan 2,5D dilakukan pada data anomali residual berdasarkan informasi geologi dan analisa struktur dengan menggunakan FHD (First Horizontal Derivative) dan SVD (Second Vertical Derivative) untuk menentukan batas struktur geologi. Hasil pemodelan menunjukkan potensi mineralisasi dengan tipe pengendapan epitermal sulfidasi rendah. Berdasarkan hasil tersebut terdapat 5 lapisan penyusun daerah penelitian yang terdiri dari breksi tuf $(2,55 \mathrm{gr} / \mathrm{cm} 3)$, tuf lapili $(2,40 \mathrm{gr} / \mathrm{cm} 3)$, tuf $(2,30 \mathrm{gr} / \mathrm{cm} 3)$, dan breksi dasit $(2,65 \mathrm{gr} / \mathrm{cm} 3)$, juga terdapat intrusi berupa andesit $(2,85 \mathrm{gr} / \mathrm{cm} 3)$.
\end{abstract}

Kata Kunci-Anomali Residual, FHD, Gravitasi, S VD.

\section{PENDAHULUAN}

$\mathrm{I}$ NDONESIA memiliki banyak potensi tambang mineral baik itu mineral logam maupun non logam. Hal ini membuat banyak industri tambang yang melakukan eksplorasi dan eksploitasi terhadap mineral di Indonesia. Mineralisasi emas di Indonesia terbentuk di busur andesitik yang aktif pada rentang waktu $20-3$ juta tahun yang lalu. Hasil penelitian sebelumnya mengidentifikasi bahwa terdapat 15 busur magmatik, 7 diantaranya adalah teridentifikasi berpotensi emas dan tembaga dan 8 lainnya belum diketahui. Temuan ini menunjukkan potensi yang umumnya berupa porphyry coppergold mineralization, skarn mineralization, high sulphidation epithermal mineralization, gold-silver-barite base metal mineralization, low sulphidation epithermal mineralizetion dan sediment hosted [1].

Lapangan "A" yang terletak di daerah Pongkor, Jawa Barat merupakan daerah yang diduga memiliki potensi mineral berupa emas yang memiliki profil daerah perbukitan tinggi yang memiliki tingg rata-rata $300 \mathrm{~m}$ sampai $900 \mathrm{~m}$ di atas permukaan laut. Memiliki relief rata-rata dari landai samoai agak curam. Daerah gunung Pongkor dan sekitarnya tersusun atas breksi tuf, tuf lapili dan intrusi andesit yang menerobos batuan sejak tersier dan endapan breksi vulkanik kuarter [2].

Oleh karena itu diperlukan survey dan analisis dalam memanfaatkan potensi mineral tersebut dengan menggunakan metode geofisika. Adapun salah satu metode geofisika yang dapat digunakan adalah dengan menggunakan metode gravitasi. Metode gravitasi merupakan pengukuran terhadap variasi medan gravitasi bumi yang diakibatkan oleh adanya perbedaan densitas yang kemudian dikenal sebagai anomali gravitasi. Medan gravitasi rata - rata di bumi sebesar $9,8 \mathrm{~m} / \mathrm{s}^{2}$ atau 980.000 mgal. Semua benda yang berada di sekitar bumi akan mempengaruhi hasil pengukuran gravitasi. Termasuk keberadaan struktur geologi maupun intrusi batuan beku yang dapat mempengaruhi nilai medan gravitasi hingga beberapa miligal.

Prinsip dasar fisika yang mendasari metode gravitasi adalah Hukum Newton tentang gaya tarik menarik. Hukum Newton menyatakan bahwa gaya tarik menarik antara dua partikel dengan massa $m_{0}$ dan $m$ yang terpisah sejauh $r-r_{0}$ dari pusat massanya sebanding dengan perkalian antara massa $m_{0}$ dengan $m$ dan berbanding terbalik dengan kuadrat jaraknya. Gaya gravitasi tersebut dapat ditulis dalam suatu persamaan sebagai berikut

$$
\vec{F}(\vec{r})=-G \frac{m_{0} m}{\left|\vec{r}-\overrightarrow{r_{0}}\right|^{2}} x \frac{\left(\vec{r}-\overrightarrow{r_{0}}\right)}{\left|\vec{r}-\overrightarrow{r_{0}}\right|}
$$

dengan $F(r)$ adalah gaya yang bekerja pada $m$ oleh karena adanya $m_{0}$ dan memiliki arah yang berlawanan dengan arah 
$\left|\vec{r}-\vec{r}_{0}\right|$ yaitu dari $m_{0}$ menuju $m$. Sedangkan $G$ adalah konstanta medan gravitasi yang besarnya $6,67428 \times 10^{-11} \mathrm{Nm}^{2} \mathrm{~kg}^{-2}$ atau $\mathrm{m}^{2} \mathrm{~kg}^{-1} \mathrm{dt}^{-2}$ [3].

Besaran yang terukur dalam metode gravitasi adalah medan gravitasi. Medan gravitasi dari partikel $m_{0}$ adalah besarnya gaya per satuan massa pada suatu titik sejauh $\left|\vec{r}-\vec{r}_{0}\right|$ dari $m$ yang dijabarkan sebagai berikut

$$
\vec{E}(\vec{r})=\frac{\vec{F}(\vec{r})}{m(\vec{r})}=-G \frac{m_{0}}{\left|\vec{r}-\vec{r}_{0}\right|^{2}} \times \frac{\left(\vec{r}-\overrightarrow{r_{0}}\right)}{\left|\vec{r}-\overrightarrow{r_{0}}\right|}
$$

dengan $E^{-}(r)$ adalah medan gravitasi, $m_{0}$ adalah massa benda, dan $\left|\vec{r}-\vec{r}_{0}\right|$ adalah jarak dari titik amat ke titik massa. Dengan menganggap bumi homogen, berbentuk sferis dan tidak berotasi, maka besarnya medan gravitasi $g$ di permukaan bumi adalah

$$
\vec{g}=\vec{E}(\vec{r})=-G \frac{M_{e}}{R_{e}^{2}} \hat{r}
$$

dengan $M_{e}$ adalah massa bumi $(\mathrm{kg})$ dan $R_{e}$ adalah jari - jari bumi (meter). Medan gravitasi $g$ biasa disebut juga sebagai percepatan gravitasi yang memiliki satuan $\left(\mathrm{m} / \mathrm{s}^{2}\right)$ atau dalam cgs dinyatakan dalam gal $\left(1 \mathrm{gal}=1 \mathrm{~cm} / \mathrm{s}^{2}\right)$.

Anomali medan gravitasi adalah nilai medan gravitasi yang ditimbulkan oleh perbedaan densitas di bawah permukaan bumi. Anomali gravitasi di topografi atau di posisi $(x, y, z)$ secara matematis diperoleh dari selisih medan gravitasi observasi di topografi dengan medan gravitasi teoritis di topografi dengan $\Delta g(x, y, z)$ adalah anomali gravitasi di topografi, $g_{o b s}(x, y, z)$ adalah medan gravitasi observasi di topografi dan $g_{\text {teoritis }}(x, y, z)$ adalah medan gravitasi teoritis di topografi [4].

Nilai medan gravitasi observasi di topografi diperoleh dari pengukuran menggunakan alat ukur gravitimeter yang telah dikoreksi dengan faktor - faktor yang mempengaruhi nilai pengukuran. Sedangkan nilai medan graviasi teoritis adalah nilai medan gravitasi di titik tersebut dihitung yang secara teoritis dengan memperhitungkan faktor posisi, elevasi, densitas rata - rata dan topografi. Nilai medan gravitasi teoritis tidak dipengaruhi efek geologi atau penyebab anomali. Data gravitasi obeservasi merupakan data mentah yang belum bisa diinterpretasi.

\section{METODE PENELITIAN}

Data yang digunakan adalah data lapangan pengukuran gravitasi dan data posisi yang telah diolah menjadi koordinat UTM dengan jumlah titik pengukuran sebanyak 193 titik. Data untuk koreksi terrain diperoleh dengan cara manual pada saat pengukuran di lapangan yaitu dengan menggunakan Hammer Chart, data tersebut berupa selisih ketinggian dari posisi titik pengukuran.

Perhitungan nilai medan gravitasi observasi diperoleh dari

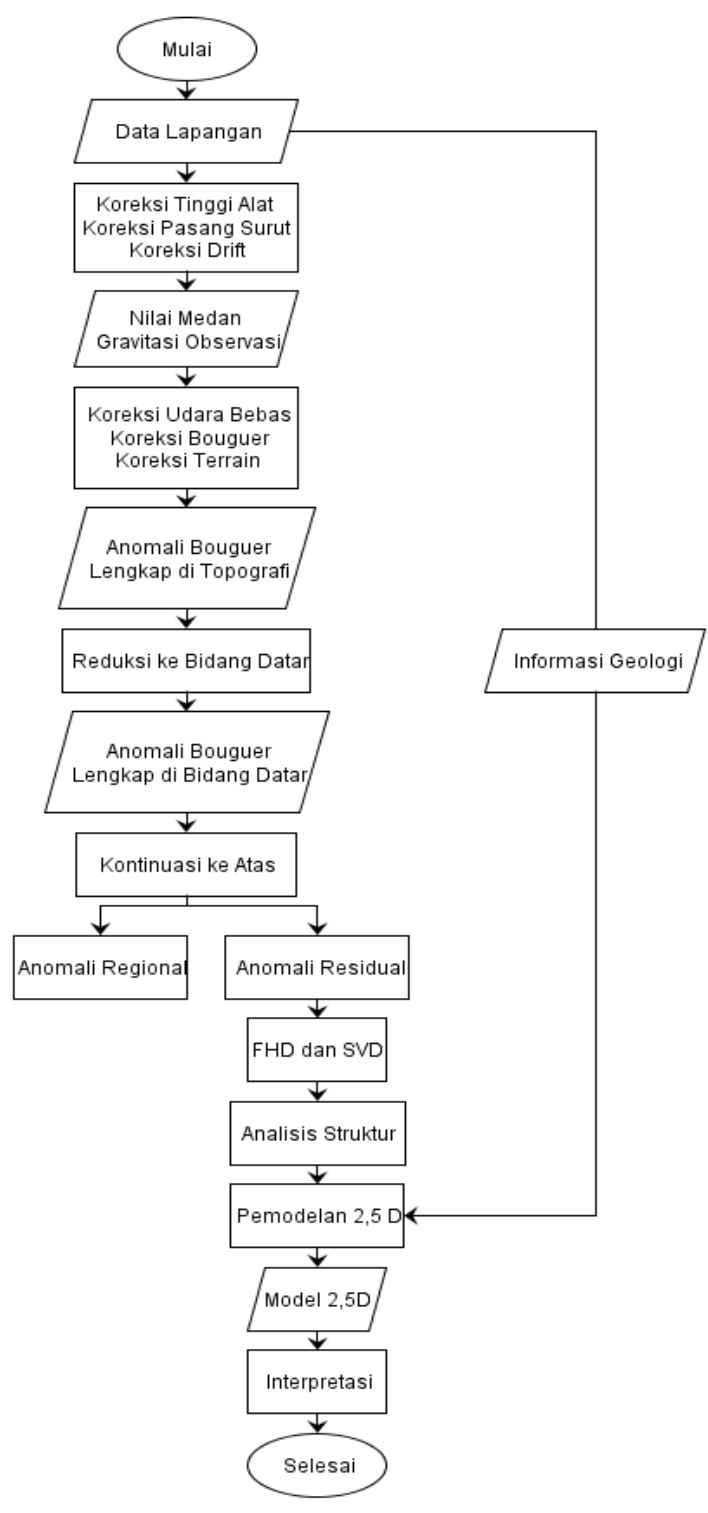

Gambar 1. Diagram alir penelitian.

data lapangan yang dikonversi ke dalam satuan mgal dan dikoreksikan dengan koreksi tinggi alat, koreksi pasang surut dan koreksi drift. Nilai medan gravitasi teoritis diperoleh dari perhitungan data posisi. Data posisi dihitung menjadi nilai medan gravitasi normal di sferoida, nilai koreksi free air, koreksi Bouguer dan koreksi terrain. Sehingga didapatkan anomali Bouguer lengkap. Setelah itu dilakukan pemisahan anomali regional dan residual dengan menggunakan metode kontinuasi ke atas. Anomali residual yang didapatkan akan digunakan untuk menganalisis bawah permukaan daerah penelitian.

Analisis struktur geologi yang dilakukan menggunakan perhitungan First Horizontal Derivative (FHD) dan Second Vertical Derivative (SVD). Aplikasi FHD dan $S V D$ dari suatu anomali gravitasi ini berguna untuk mengidentifikasi bidang batas sesar serta kontak litologi yang terdapat di daerah penelitian bergantung pada respon FHD-SVD nya. Bidang kontak sesar dengan nilai maksimum atau minimum pada 


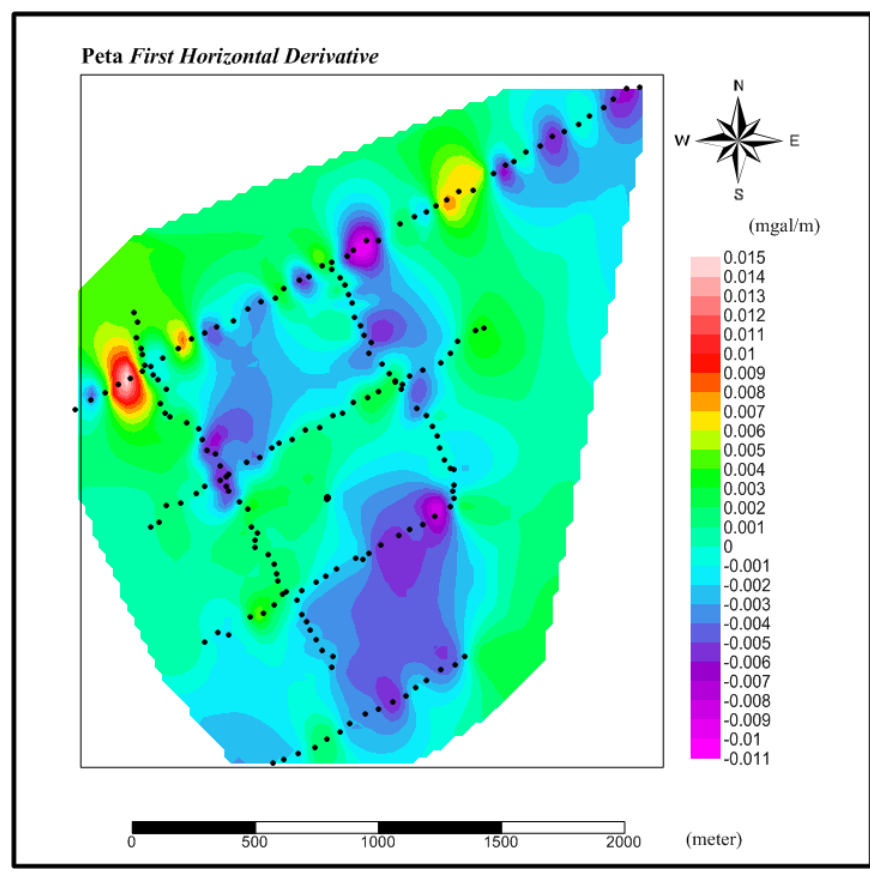

Gambar 2. Peta anomali residual.

penampang $F H D$ berkorelasi dengan nilai sama dengan nol pada penampang $S V D$, hasil tersebut dapat diinterpretasikan sebagai bidang batas struktur geologi.

Pemodelan dilakukan untuk meng Gambarkan kondisi geologi sehingga dapat ditampilkan target berupa struktur geologi dan perlapisan di bawah permukaan. Parameter yang dimasukkan pada saat pemodelan adalah variasi nilai densitas batuan. Besar nilai densitas batuan diperoleh melalui informasi litologi daerah penelitian. Parameter tersebut diubah sedemikian rupa sehingga mendapatkan kurva yang cocok antara model yang telah dibuat dengan respon anomalinya.

\section{HASIL DAN PEMBAHASAN}

Data yang digunakan adalah data lapangan pengukuran gravitasi dan data posisi yang telah diolah menjadi koordinat UTM dengan jumlah titik pengukuran sebanyak 193 titik. Daerah penelitian menunjukkan dominasi daerah perbukitan yang diketahui dari informasi geologi bahwa daerah penelitian terletak di daerah yang memiliki dataran tinggi dan dekat dengan Gunung Pongkor. Titik pengukuran untuk pengambilan data dilakukan di kawasan pertambangan milik PT. ANTAM (Persero) Tbk.

Dari hasil pembacaan data yang diberikan oleh alat pengukuran perlu dilakukan koreksi untuk menghilangkan pengaruh yang bukan berasal dari objek geologi yang akan diamati. Tahapan-tahapan koreksi dilakukan hingga mendapatkan tahapan akhir koreksi yang menghasilkan anomali Bouguer. Anomali Bouguer lengkap di topografi sendiri masih mengalami distorsi data akibat tidak homogennya topografi sehingga masih perlu dilakukan reduksi ke bidang datar. Hal ini dilakukan untuk menyeragamkan sehingga mempermudah interpretasi data.

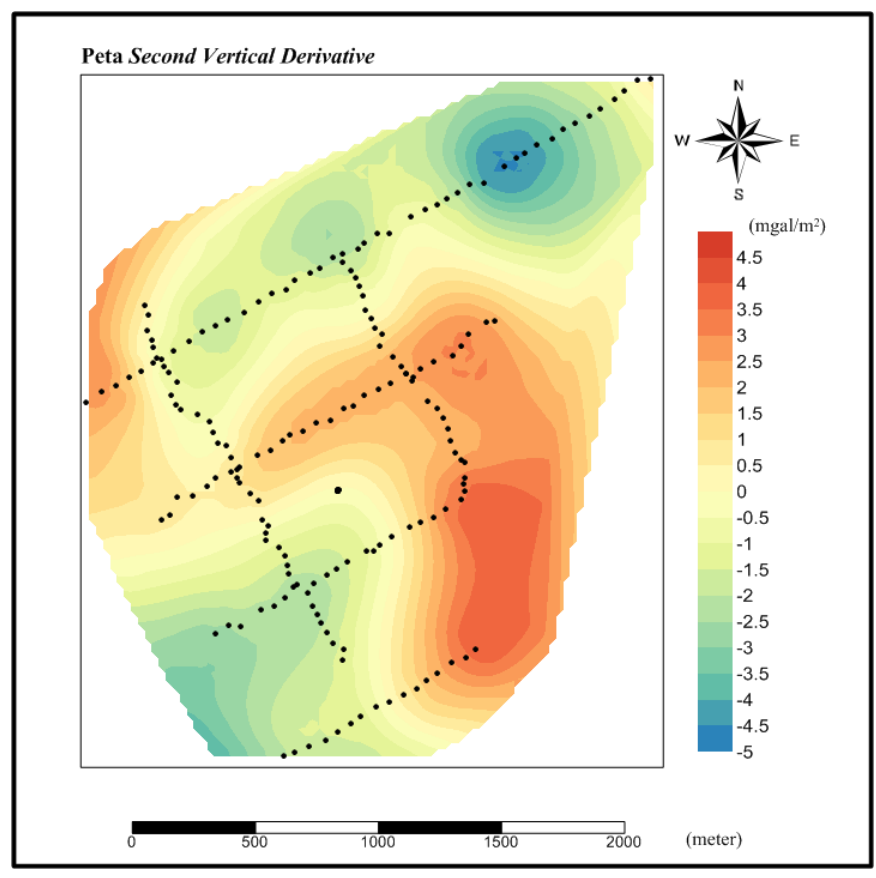

Gambar 3. Peta second vertical derivative.

Data anomali Bouguer yang dihasilkan dari pengolahan merupakan data campuran dari anomali regional dan anomali residual, sehingga data yang telah direduksi ke bidang datar perlu dilakukan pemisahan untuk memisahkan anomali regional dan anomali residual. Adapun metode yang digunakan pada penelitian ini adalah dengan menggunakan metode pemisahan kontinuasi ke atas. Metode ini digunakan untuk menghilangkan efek lokal sehingga yang didapat adalah kecenderungan anomali regionalnya saja. Hasil yang diperoleh kemudian dikurangkan terhadap anomali Bouguer lengkap yang telah tereduksi pada bidang datar sehingga diperoleh anomali Bouguer lengkap residual yang siap diinterpretasi.

Dalam melakukan proses interpretasi bawah permukaan daerah penelitian dibutuhkan kedalaman yang dangkal. Hal ini dikarenakan pada kedalaman yang cukup dangkal telah mengalami proses erosi dan deformasi batuan. Sehingga diperlukan anomali residual untuk mengidentifikasi bawah permukaan daerah tersebut.

Anomali residual merupakan anomali lokal yang berada di daerah penelitian. Sehingga hasil dari anomali residual ini dapat digunakan untuk menjelaskan struktur geologi di sekitar permukaan. Anomali ini diperoleh dari selisih antara anomali Bouguer dengan anomali regional. Hasil pengolaha menunjukkan rentang nilai yang cukup kecil pada anomali medan gravitasi residual. Hal ini dikarenakan batuan penyusun daerah penelitian didominasi batuan yang hampir seragam yakni batuan beku.

Dari anomali medan gravitasi residual ini kemudian digunakan untuk menginterpretasi dengan menganalisis struktur dan melakukan pemodelan untuk mengetahui kondisi bawah permukaan. Analisis struktur menggunakan metode $F H D$ dan $S V D$. Nilai dari $F H D$ anomali medan gravitasi merupakan perubahan nilai anomali medan gravitasi dari satu 


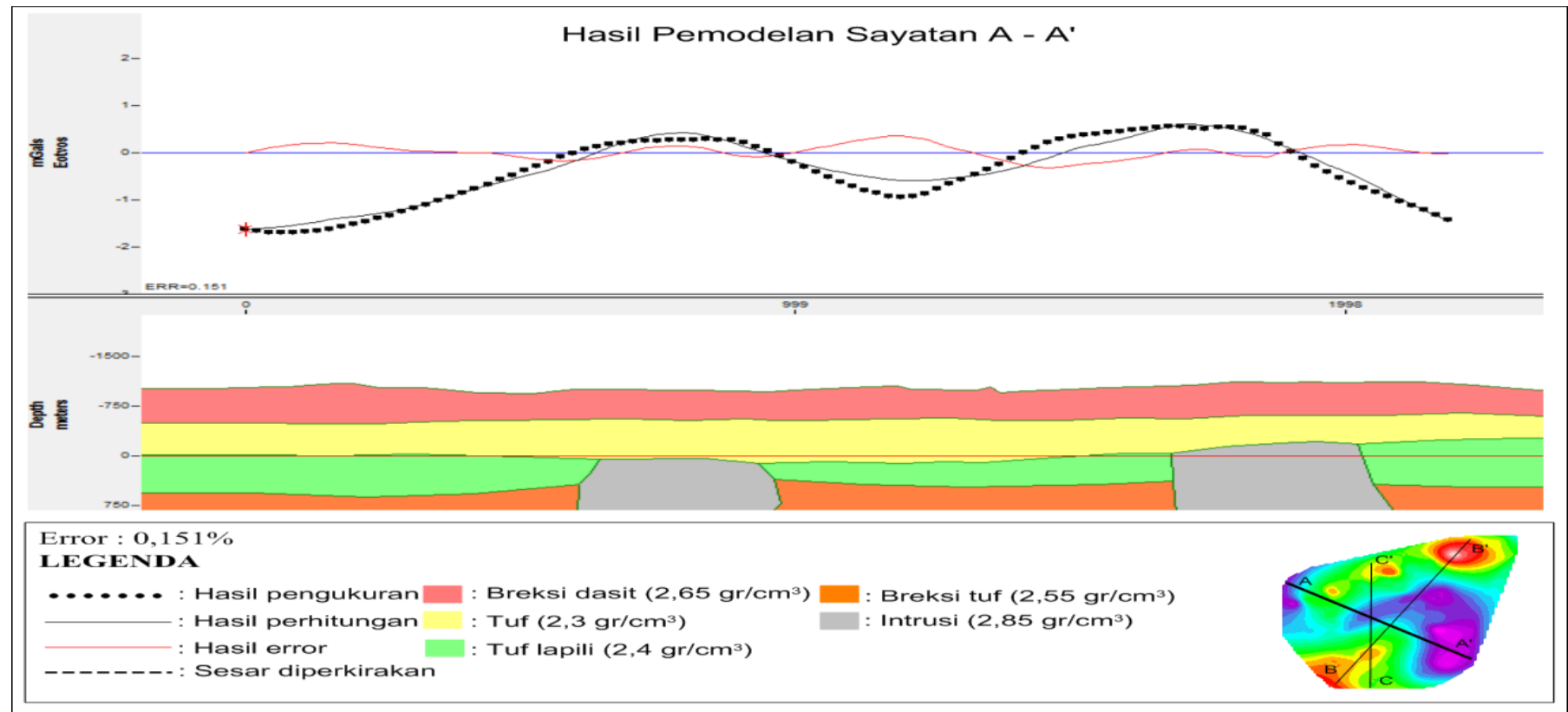

Gambar 4. Hasil pemodelan sayatan A - A'.

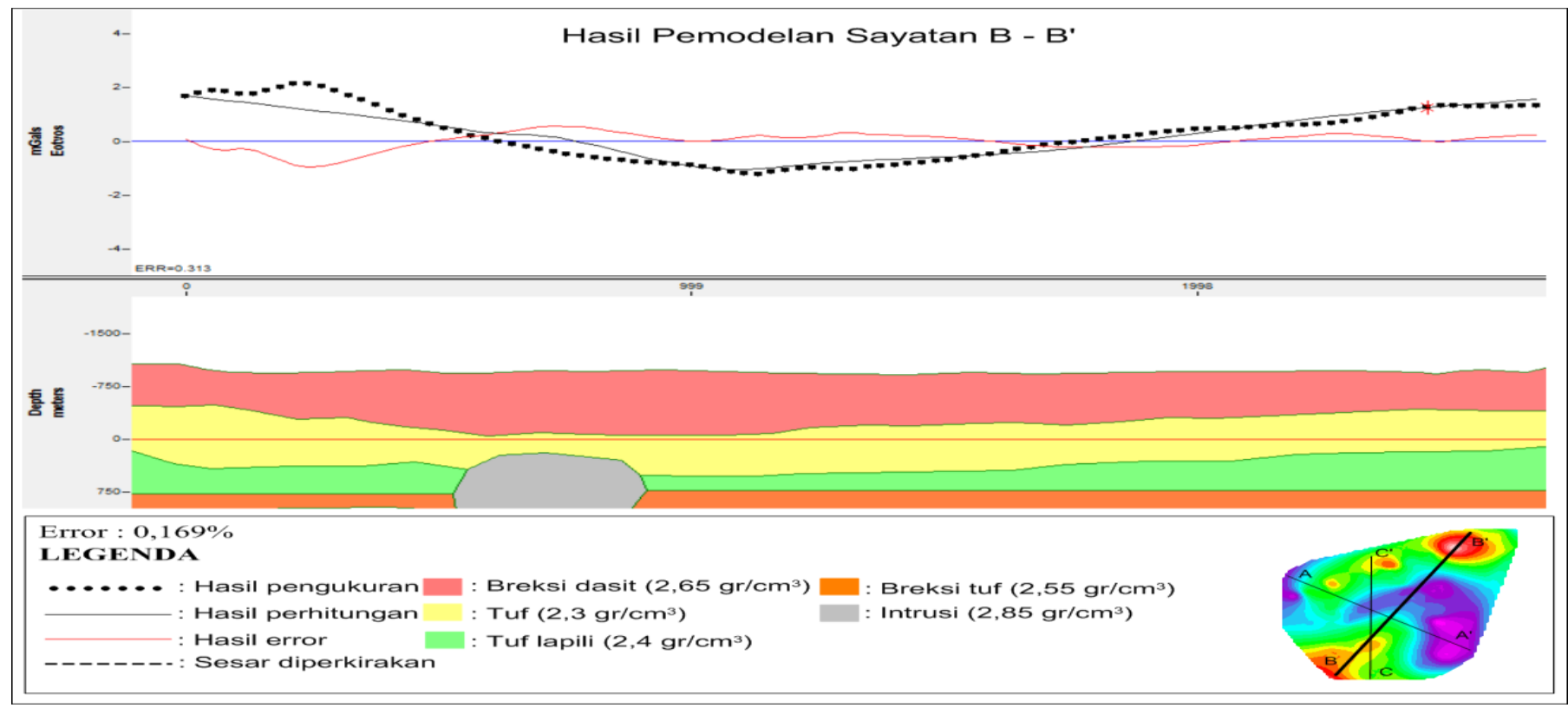

Gambar 5. Hasil pemodelan sayatan B - B'.

titik ke titik lainnya secara horizontal dengan jarak tertentu yang dapat digunakan untuk menunjukkan suatu struktur geologi berdasarkan anomali medan gravitasi. Sedangkan SVD anomali medan gravitasi dilakukan untuk memunculkan efek dangkal dari pengaruh regionalnya yang digunakan untuk mendeteksi jenis struktur patahan normal atau patahan naik.

Hasil perhitungan dengan menggunakan metode FHD dilakukan pada arah $0^{\circ}, 45^{\circ}, 90^{\circ}$, dan $135^{\circ}$. Dari Gambar 2 menunjukkan jangkauan nilai dari $-0.011 \mathrm{mgal} / \mathrm{m}$ hingga 0.015 $\mathrm{mgal} / \mathrm{m}$. Peta kontur $F H D$ yang sudah diplotkan kemudian dikorelasikan dengan peta dari SVD agar dapat ditentukan batas struktur geologinya.

Hasil analisa derivatif turunan kedua dengan menggunakan metode Elkins ditunjukkan pada Gambar 3. Dari peta kontur yang ditunjukkan adapun diketahui jangkauan nilai dari hasil perhitungannya adalah $-5 \mathrm{mgal} / \mathrm{m}^{2}$ hingga $4,5 \mathrm{mgal} / \mathrm{m}^{2}$.

Dari hasil pengamatan melalui peta kontur $S V D$ yang dikorelasikan dengan peta $F H D$, pada bagian barat laut hingga menerus ke bagian tenggara daerah penelitian terdapat nilai yang sama dengan nol dimana pada daerah ini diperkirakan adanya sesar. Keberadaan sesar ini juga ditemukan pada informasi geologi yang menyatakan bahwa sesar ini menjadi bagian dari sesar Capek Kawung dan sesar Kubang Cicau dimana jika dikorelasikan dengan data geologi yang dimiliki oleh PT. ANTAM (Persero) Tbk, sesar Capek Kawung dan sesar Kubang Cicau merupakan sesar naik.

Pada bagian timur laut pada peta $S V D$ yang berarah memanjang hingga ke arah barat daya menunjukkan kelurusan 


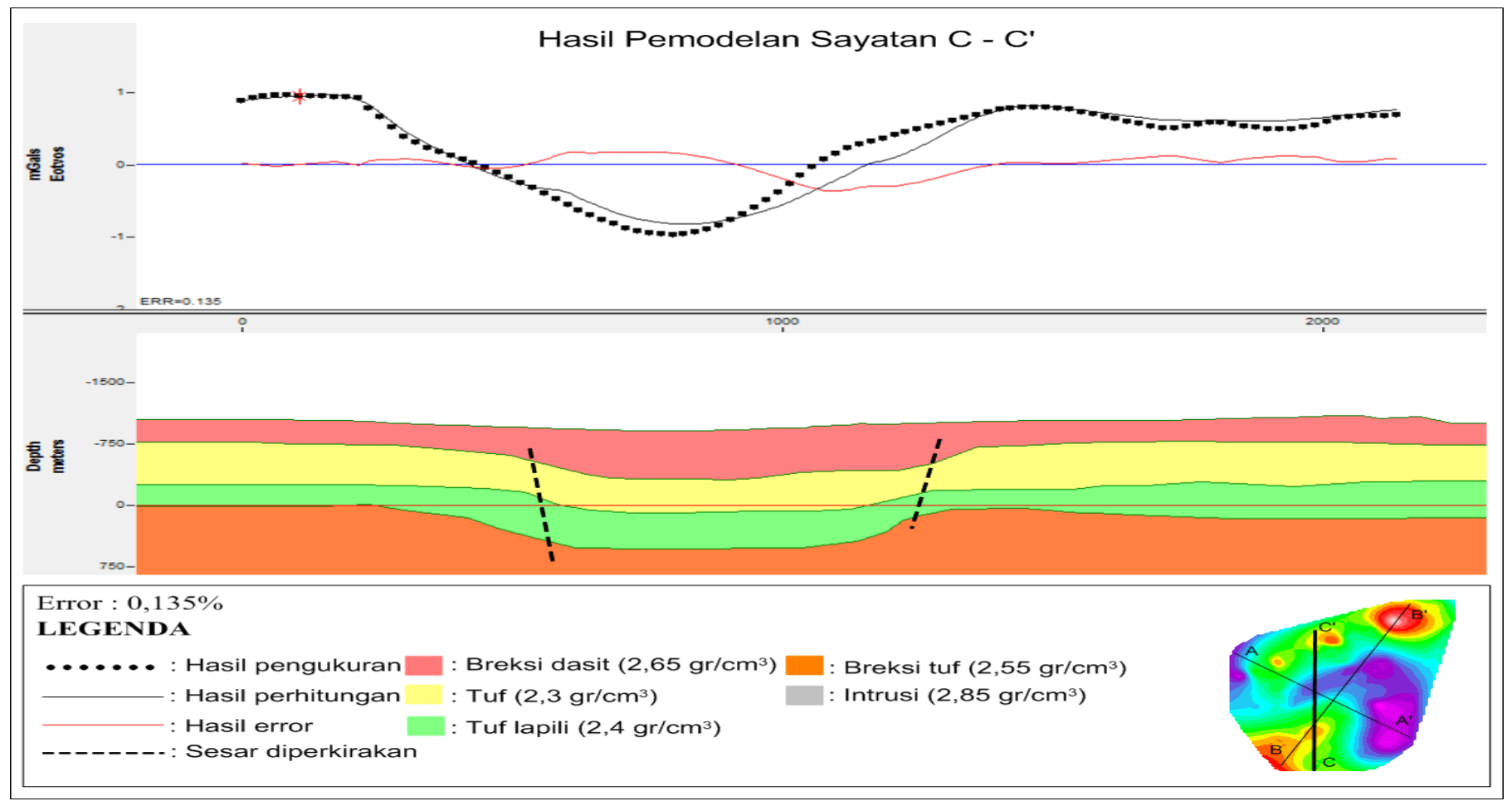

Gambar 6. Hasil pemodelan sayat an C-C'.

yang memiliki nilai sama dengan nol. Pada daerah ini diperkirakan adanya sesar pada bagian ini. Hal ini juga dapat dikorelasikan dengan data geologi bahwa pada arah timur laut - barat daya ditemukan sesar geser yang menurun.

Dari hasil pemodelan yang dilakukan menunjukkan adanya lima penyusun batuan yang dominan dalam menjadi sumber anomali di daerah penelitian. Adapun densitas batuan yang ditemukan ini antara lain breksi tuf sekitar $2,55 \mathrm{gr} / \mathrm{cm}^{3}$, tuf lapili sekitar 2,4 $\mathrm{gr} / \mathrm{cm}^{3}$, breksi dasit sekitar $2,65 \mathrm{gr} / \mathrm{cm}^{3}$, dan intrusi andesit sekitar $2,85 \mathrm{gr} / \mathrm{cm}^{3}$.

Pada sayatan A - A' yang ditunjukkan pada Gambar 4 menunjukkan lima batuan penyusun daerah penelitian. Adapun urutan batuan penyusun itu mulai dari breksi dasit, tuf, tuf lapilli, dan breksi serta ditemukan adanya intrusi andesit yang ditemukan pada jarak sekitar 700 meter dari permukaan sayatan A - A'. Dugaan adanya intrusi ini ditunjukkan dengan adanya puncak anomali yang tinggi.

Dari hasil pemodelan B - B' yang ditunjukkan pada Gambar 5 menunjukkan kemiripan dengan sayatan A - A'. Pada jarak sekitar 700 meter dari permukaan sayatan B - B' ditemukan adanya anomali yang tinggi sehingga dapat diinterpretasikan sebagai dugaan adanya intrusi. Intrusi ini menerobos batuan tuf.

Hasil pemodelan pada sayatan C - C'yang ditunjukkan pada Gambar 6 menunjukkan dominasi empat batuan penyusun yakni breksi dasit, tuf, lapilli dan breksi tuf. Dari hasil pemodelan juga menunjukkan adanya dugaan 2 sesar dari hasil sayatan C - C'. Pada jarak sekitar 500 meter dan 1500 meter dari sayatan $\mathrm{C}-\mathrm{C}^{\prime}$ diperkirakan adanya sesar menurun.

Dari hasil yang telah ditunjukkan pada peta kontur anomali residual dan hasil pemodelan di beberapa sayatan di daerah penelitian menunjukkan adaya anomali gravitasi yang bernilai tinggi yang diduga sebagai adanya intrusi. Selanjutnya jika dihubungkan dengan hasil analisis struktur dari peta FHD dan $S V D$ ditemukan dugaan adanya sesar yang kemudian diperkuat dengan adanya informasi geologi dari daerah penelitian. Hal ini menunjukkan dugaan adanya proses mineralisasi di daerah penelitian. Intrusi sendiri diketahui memiliki peranan penting dalam proses eksplorasi mineral yakni sebagai sumber panas yang mengandung mineral logam dan sebagai tempat yang baik dalam proses mineralis asi jika berteks tur porfiritik.

\section{KESIMPULAN}

Hasil anomali gravitasi residual menunjukkan adanya anomali tinggi yang diperkirakan sebagai adanya intrusi batuan andesit dan adanya sesar yang ditunjukkan pada daerah penelitian. Batas struktur geologi dengan analisa $F H D$ dan $S V D$ menunjukkan adanya sesar yang menerus dari arah timur laut - barat daya dan barat laut - tenggara. Berdasarkan hasil pemodelan yang diperoleh didapatkan lima lapisan penyusun batuan di daerah penelitian, yakni breksi tuf $2,55 \mathrm{gr} / \mathrm{cm}^{3}$, tuf lapilli $2,40 \mathrm{gr} / \mathrm{cm}^{3}$, tuf $2,3 \mathrm{gr} / \mathrm{cm}^{3}$, breksi dasit $2,65 \mathrm{gr} / \mathrm{cm}^{3}$, serta ditemukan adanya intrusi andesit dengan densitas $2,85 \mathrm{gr} / \mathrm{cm}^{3}$.

\section{UCAPAN TERIMA KASIH}

Teriama kasih kepada PT. ANTAM (Persero) Tbk. yang memberikan dukungan data gravitasi dalam penelitian ini,

\section{DAFTAR PUSTAKA}

[1] Supeno and W. Nugroho, Agung T. Utama, "Survei Potensi 
Sumber Daya Mineral di Kecamatan Silo Kbupaten Jember dengan Menggunakan Metode Potensial Diri," J. Fis. dan Apl., vol. 5, no. $1,2009$.

[2] A. Basuki, D. A. Sumanagara, and D. Sinambela, "The Gunung Pongkor Gold-Silver Deposit, West Java, Indonesia.," J. Geochemical Explor., vol. 50, pp. 371-391, 1994.
New York: Press New York, 1990.

A. Dermawan, "Rekonseptualisasi dan Pemograman Reduksi Data Gravitasi serta Pemetaan ke Koordinat Teratur (Gridding) Menggunakan Bahasa Pemograman Visual Basic," Yogyakarta, 2010 . 